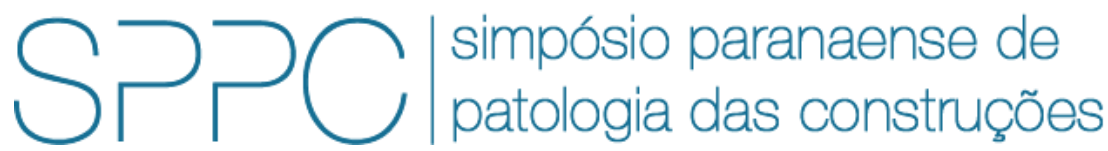

ISSN 2526-7248 artigo 2SPPC1026, pp. 315-328, 2017

\title{
Aplicação do modelo matemático para ranqueamento de obras de arte especiais desenvolvido pelo Escritório Modelo de Engenharia Civil - EMEA/UFPR - Um estudo de caso
}

\author{
Cezar Falavigna ${ }^{1}$ e Mauro Lacerda Santos Filho² \\ ${ }^{1}$ Graduando de Engenharia Civil, Universidade Federal do Paraná, cezarfalavigna@gmail.com \\ 2 Professor PhD., Universidade Federal do Paraná, mauro.lacerda@ufpr.br
}

\begin{abstract}
Resumo: O papel da engenharia civil não encerra quando uma obra é entregue, já que deve ser garantido que a estrutura suporte as solicitações durante sua vida útil. Para isso, algumas manutenções são necessárias a fim de garantir que a edificação consiga chegar ao limite desse período. Porém, no Brasil, principalmente em obras públicas, isso não acontece com a frequência devida, especialmente com Obras de Arte Especiais, ainda mais se somado as restrições orçamentárias impostas recentemente. Portanto, criar um modelo de ranqueamento, no qual, podese focar nas estruturas com as condições mais críticas, é de suma importância para o planejamento e gestão dessas obras. Esse artigo propõe a aplicação de um modelo matemático de avaliação desenvolvido no Escritório Modelo de Engenharia Civil - EMEA da Universidade Federal do Paraná.
\end{abstract}

Palavras-chave: Obras de Arte Especiais, Pontes, Viadutos, Ranqueamento, Modelo Matemático.

Abstract: In order to reach the life span established on the beginning of the project, a structure must go through maintenance. In Brazil, that isn't done very often, especially on buildings under the government jurisdiction. Some of those are bridges. If added budget restrictions, it is very important to create a way to identify the bridges in the worst conditions, so that the management responsible ones can plan which structures have priority on maintenance. To do so, a ranking model is needed to rate the bridges. This article propose an application of a mathematical evaluation model developed by the Civil Engineering Model Office from the Paraná State Federal University.

Keywords: Bridges, Ranking model, Mathematical model. 
FALAVIGNA, C.; SANTOS FILHO, M L., APLICAÇÃO DO MODELO MATEMÁTICO PARA RANQUEAMENTO DE OBRAS DE ARTE ESPECIAIS DESENVOLVIDO PELO ESCRITÓRIO MODELO DE ENGENHARIA CIVIL - EMEA/UFPR - UM ESTUDO DE CASO. $2^{\circ}$ Simpósio Paranaense de Patologia das Construções (20 SPPC), artigo 2SPPC1026, pp. 315-328, 2017. DOI:

\section{Introdução}

A conservação de estruturas se faz parte essencial durante a utilização da obra. Todas as edificações quando dimensionadas, construídas e operadas conforme normas, possuem um período de vida útil. Em qualquer estrutura, para que esta consiga atingir esse tempo, deve-se passar por intervenções para readequação.

Quando essa etapa é negligenciada, os custos decorrentes dessa falta de manutenção sobem, ou seja, os gastos provenientes de manutenções preventivas são menos onerosos que as corretivas, conforme afirma Sitter [1], além disso o desempenho é estendido no tempo, segundo Lichtenstein [2].

Principalmente para a esfera pública, na qual existem restrições de orçamento, ou ainda, existem âmbitos ou itens prioritários, no caso de mal funcionamento de uma estrutura, isso pode acarretar em complicações financeiras, logísticas, temporais ou mesmo de conforto que afetam muitas pessoas e setores.

Um exemplo disso seria a inoperabilidade de uma obra de arte especial (OAE). Dessa situação já é possível prever problemas em entregas, circulação de mercadorias, aumento dos custos de transporte, emissão de gases poluentes, tempo de viagem, ou até mesmo, o isolamento de uma determinada região.

Por essa razão, o gerenciamento de pontes e viadutos é essencial para que a deterioração da estrutura não atinja o ponto de impossibilitar sua operação. Decorrente disso, um modelo de avaliação das obras precisa ser implementado afim de saber a situação de conservação na qual a estrutura se encontra.

\section{Metodologia}

O modelo matemático desenvolvido na Universidade Federal do Paraná (UFPR) se baseia em uma metodologia inicialmente utilizada na Áustria e Eslovênia, descritos no relatório COST 345 [3]. Porém, os seus índices foram atualizados para as condições brasileiras. A formulação é descrita, a seguir, pela equação 1:

$$
R=\sum V_{d}=\sum B_{i} * K_{1 i} * K_{2 i} * K_{3 i} * K_{4 i}
$$

$\mathrm{Vd}=$ Valor do dano;

$\mathrm{Bi}=$ Valor associado ao tipo de dano "i" sobre a segurança e/ou durabilidade;

$\mathrm{K} 1 \mathrm{i}$ = fator do elemento da estrutura, em função de sua importância no contexto da estrutura como um todo;

$\mathrm{K} 2 \mathrm{i}$ = fator indicativo da intensidade do tipo de dano "i";

$\mathrm{K} 3 \mathrm{i}$ = fator relativo à extensão da propagação do tipo de dano i nos elementos inspecionados;

K4i = fator enfatizante da urgência da intervenção para o dano "i”.

Relatado no "Bulletin 243" do CEB [4], os índices possuem um intervalo de variação. O primeiro a ser explicado será o valor associado ao tipo de dano. Esse valor está associado à manifestação que a obra apresenta e varia entre 1,00 e 5,00, conforme a severidade da deterioração. Quanto mais insegurança à estrutura a manifestação 
FALAVIGNA, C.; SANTOS FILHO, M L., APLICAÇÃO DO MODELO MATEMÁTICO PARA RANQUEAMENTO DE OBRAS DE ARTE ESPECIAIS DESENVOLVIDO PELO ESCRITÓRIO MODELO DE ENGENHARIA CIVIL - EMEA/UFPR - UM ESTUDO DE CASO. $2^{\circ}$ Simpósio Paranaense de Patologia das Construções (20 SPPC), artigo 2SPPC1026, pp. 315-328, 2017. DOI: $10.4322 / 2$ SPPC.2017.026

patológica gera, maior será o valor do parâmetro, como descrito na tabela 1, a seguir. Essa tabela não ilustra todos os danos presentes no modelo, porém ilustra a variação entre os intervalos dos valores.

Tabela 1: Valores para o parâmetro B - manifestações patológicas

\begin{tabular}{|c|c|}
\hline Nome & B \\
\hline Fissura em linha vertical & 3,00 \\
\hline Fissura em linha horizontal & 3,00 \\
\hline Fissura próxima ao apoio com superestrutura & 3,00 \\
\hline Fissura mapeada & 3,00 \\
\hline Manchas de fogo & 1,00 \\
\hline Fragmentação por fogo & 2,00 \\
\hline Mancha de umidade & 1,00 \\
\hline Eflorescências, com surgimento de manchas esbranquiçadas & 1,00 \\
\hline Desgaste superficial & 1,00 \\
\hline Corrosão da armadura (apenas mancha de corrosão) & 2,00 \\
\hline Corrosão da armadura com desplacamento de concreto & 3,00 \\
\hline Corrosão da armadura com desplacamento e perda de seção & 4,00 \\
\hline Corrosão da armadura com desplacamento e rompimento da barra & 5,00 \\
\hline Armadura exposta por deficiência de cobrimento, sem corrosão & 2,00 \\
\hline Concreto segregado & 2,00 \\
\hline Nicho de concretagem & 2,00 \\
\hline Forma aderida à superfície do concreto & 1,00 \\
\hline Desalinhamento & 2,00 \\
\hline Deslocamento & 2,00 \\
\hline Falta de prumo & 2,00 \\
\hline Deslizamento gerando esforços imprevistos & 3,00 \\
\hline Recalque do aterro de aproximação & 3,00 \\
\hline Obstrução, sem causar esforços imprevistos & 2,00 \\
\hline Abertura excessiva & 2,00 \\
\hline Recapeamento irregular & 2,00 \\
\hline Desnível & 3,00 \\
\hline Inexistência de drenos & 2,00 \\
\hline Entupimento de drenos & 2,00 \\
\hline Deficiência nas pingadeiras e buzinotes & 2,00 \\
\hline Buraco & 3,00 \\
\hline Desgaste & 1,00 \\
\hline Choque de veículos & 3,00 \\
\hline Guarda-corpo rompido ou inexistente & 2,00 \\
\hline Ausência de passeio em área urbana & 2,00 \\
\hline Transição perigosa (sem acostamento) & 2,00 \\
\hline Barreira não padronizada & 2,00 \\
\hline Vegetação incrustada & 1,00 \\
\hline Corrosão em elementos metálicos & 3,00 \\
\hline Corrosão em elementos metálicos com perda de seção & 4,00 \\
\hline
\end{tabular}

O segundo parâmetro é o K1, referente ao elemento no qual a manifestação patológica se encontra. Assim como o B, algumas partes constituintes da obra de arte especial possuem pesos maiores do que outros. Esse valor varia de 0,10 até 
FALAVIGNA, C.; SANTOS FILHO, M L., APLICAÇÃO DO MODELO MATEMÁTICO PARA RANQUEAMENTO DE OBRAS DE ARTE ESPECIAIS DESENVOLVIDO PELO ESCRITÓRIO MODELO DE ENGENHARIA CIVIL - EMEA/UFPR - UM ESTUDO DE CASO. $2^{\circ}$ Simpósio Paranaense de Patologia das Construções (2० SPPC), artigo 2SPPC1026, pp. 315-328, 2017. DOI:

0,60 ilustrado abaixo (Tabela 2). Essa mostra, parcialmente, os pesos dos elementos disponíveis no modelo.

Tabela 2: Valores para o parâmetro K1 - elemento estrutural

\begin{tabular}{|c|c|}
\hline Nome & K1 \\
\hline Laje de concreto armado & 0,40 \\
\hline Laje de concreto protendido & 0,40 \\
\hline Ponte em laje de concreto armado & 0,60 \\
\hline Ponte em laje de concreto protendido & 0,60 \\
\hline Travessa de concreto armado & 0,40 \\
\hline Travessa de concreto protendido & 0,40 \\
\hline Viga de concreto armado & 0,60 \\
\hline Viga de concreto protendido & 0,60 \\
\hline Viga metálica & 0,60 \\
\hline Viga caixão de concreto armado & 0,60 \\
\hline Viga caixão de concreto protendido & 0,60 \\
\hline Viga caixão metálica & 0,60 \\
\hline Transversina portante de concreto armado & 0,30 \\
\hline Transversina portante de concreto protendido & 0,30 \\
\hline Transversina de ligação de concreto armado & 0,20 \\
\hline Pilar em colunas de concreto armado & 0,40 \\
\hline Pilar parede de concreto armado & 0,40 \\
\hline Contraventamento de pilar de concreto armado & 0,40 \\
\hline Aparelho de apoio de neoprene fretado & 0,40 \\
\hline Aparelho de apoio de teflon & 0,40 \\
\hline Aparelho de apoio de rolo metálico & 0,40 \\
\hline Aparelho de apoio de pot bearing fixo & 0,40 \\
\hline Aparelho de apoio de freyssinet & 0,40 \\
\hline Articulação metálica & 0,40 \\
\hline Dente Gerber de concreto armado & 0,60 \\
\hline Dente Gerber metálico & 0,60 \\
\hline Encontro - Parede frontal de concreto armado & 0,10 \\
\hline Encontro - Parede lateral e vigas de concreto armado & 0,20 \\
\hline Encontro - Laje de concreto armado & 0,10 \\
\hline Encontro - Cortina de concreto armado & 0,20 \\
\hline Muro de arrimo de concreto & 0,40 \\
\hline Muro de terra armada & 0,30 \\
\hline Talude revestido em concreto & 0,40 \\
\hline Estaca de concreto armado & 0,40 \\
\hline Estaca metálica & 0,40 \\
\hline Bloco de concreto armado & 0,40 \\
\hline Tubulão de concreto armado & 0,40 \\
\hline Junta de dilatação elastomérica & 0,20 \\
\hline Pavimento asfáltico & 0,20 \\
\hline Pavimento de concreto & 0,20 \\
\hline Calçada de concreto armado & 0,20 \\
\hline Barreira & 0,10 \\
\hline Defensa metálica & 0,10 \\
\hline Guarda rodas & 0,10 \\
\hline Guarda corpo de concreto armado & 0,10 \\
\hline
\end{tabular}


FALAVIGNA, C.; SANTOS FILHO, M L., APLICAÇÃO DO MODELO MATEMÁTICO PARA RANQUEAMENTO DE OBRAS DE ARTE ESPECIAIS DESENVOLVIDO PELO ESCRITÓRIO MODELO DE ENGENHARIA CIVIL - EMEA/UFPR - UM ESTUDO DE CASO. $2^{\circ}$ Simpósio Paranaense de Patologia das Construções (20 SPPC), artigo 2SPPC1026, pp. 315-328, 2017. DOI:

\begin{tabular}{cc} 
Nome & $10.4322 / 2$ SPPC.2017.026 \\
Guarda corpo metálico & 0,10 \\
Operação & 0,20 \\
Drenagem & 0,20 \\
Sinalização & 0,10 \\
Reforço de viga - Armadura principal passiva & 0,60 \\
Reforço de viga - Cabo de proteção externo & 0,60 \\
Reforço de pilar - Encamisamento & 0,40 \\
Aterro de acesso & 0,20 \\
Laje de aproximação & 0,20 \\
Treliça de concreto armado & 0,50 \\
\hline
\end{tabular}

A seguir, o índice $\mathrm{K} 2$ refere-se à intensidade do dano, ou seja, se a manifestação abrange uma área grande ou pequena de um determinado elemento. Esses valores possuem um intervalo entre 0,50 ou 2,00, conforme ilustra o "Bulletin 243" do CEB. [4]

Tabela 3: Valores para o parâmetro K2 - intensidade da manifestação patológica

\begin{tabular}{|c|c|c|c|}
\hline Tipo & Grau & Critério & K2 \\
\hline 0 & Insignificante & $\begin{array}{l}\text { Dano irrelevante, em menos de } 3 \% \text { da } \\
\text { área total do elemento }\end{array}$ & 0,00 \\
\hline I & Pequeno & $\begin{array}{c}\text { Dano pequeno, entre } 3 \% \text { e } 10 \% \text { da área } \\
\text { total do elemento }\end{array}$ & 0,50 \\
\hline II & Intermediário & $\begin{array}{l}\text { Dano intermediário, confiando em uma } \\
\text { área entre } 10 \% \text { a } 25 \% \text { total do elemento }\end{array}$ & 1,00 \\
\hline III & Grande & $\begin{array}{c}\text { Dano grande, de } 25 \% \text { a } 75 \% \text { da área } \\
\text { total do elemento ou em muitos lugares } \\
\text { de um elemento estrutural }\end{array}$ & 1,50 \\
\hline IV & Imenso & $\begin{array}{l}\text { Dano muito grande, na maior parte da } \\
\text { área de um elemento, mais de } 75 \% \text { da } \\
\text { área total do elemento }\end{array}$ & 2,00 \\
\hline
\end{tabular}

Os valores de K3 são associados à extensão de propagação dos danos em todos os elementos com a mesma caracterização. A variação desse parâmetro é de 0,5 a 2,00, conforme designado na tabela 4, a seguir:

Tabela 4: Valores para o parâmetro K3 - extensão da propagação do dano

\begin{tabular}{cc}
\hline Critério & K3 \\
\hline Dano aparece em menos de 10\% dos elementos estruturais da OAE & 0,50 \\
Dano aparece entre $10 \%$ e $25 \%$ dos elementos estruturais da OAE & 1,00 \\
Dano aparece entre $25 \%$ e $75 \%$ dos elementos estruturais da OAE & 1,50 \\
Dano aparece entre $75 \%$ e $100 \%$ dos elementos estruturais da OAE & 2,00 \\
\hline
\end{tabular}

Por último, os valores representativos de K4 variam entre 1,00 e 5,00 e esse índice está associado à intervenção dos danos apresentados, a seguir, na tabela 5: 
FALAVIGNA, C.; SANTOS FILHO, M L., APLICAÇÃO DO MODELO MATEMÁTICO PARA RANQUEAMENTO DE OBRAS DE ARTE ESPECIAIS DESENVOLVIDO PELO ESCRITÓRIO MODELO DE ENGENHARIA CIVIL - EMEA/UFPR - UM ESTUDO DE CASO. $2^{\circ}$ Simpósio Paranaense de Patologia das Construções (20 SPPC), artigo 2SPPC1026, pp. 315-328, 2017. DOI:

Tabela 5: Valores para o parâmetro K4 - urgência de intervenção no dano

\begin{tabular}{ccc}
\hline Classificação & Critério & K4 \\
\hline Não urgente & Dano aparece em menos de 10\% dos elementos & 0,50 \\
Dano a reparar & $\begin{array}{c}\text { estruturais da OAE } \\
\text { Dano aparece entre } 10 \% \text { e } 25 \% \text { dos elementos } \\
\text { estruturais da OAE }\end{array}$ & 1,00 \\
Reparo imediato & $\begin{array}{c}\text { Dano aparece entre } 25 \% \text { e } 75 \% \text { dos elementos } \\
\text { estruturais da OAE }\end{array}$ & 1,50 \\
Limitação de carga & $\begin{array}{c}\text { Dano aparece entre 75\% e 100\% dos elementos } \\
\text { estruturais da OAE }\end{array}$ & 2,00 \\
\hline
\end{tabular}

No entanto, somente analisar as obras pelas manifestações que apresentam não uniformizaria a avaliação, já que obras com maior metragem podem, ou pelo menos, possuem mais elementos e área total para apresentar danos. Além disso, diferentes morfologias apresentam pesos diferentes para os elementos, o que não deixa homogênea a avaliação.

Deve-se então aplicar um modelo relativo para considerar a forma da estrutura. Para isso, o valor oriundo do somatório dos produtos $(\mathrm{Vd})$ é dividido por um valor de referência $(V d, r e f)$. Esse valor de referência é gerado pegando todos os danos que podem ocorrer na obra, multiplicados pelos valores máximo de intensidade e extensão $(K 2=K 3=2,00)$ e pelo valor unitário de urgência $(K 4=1,00)$. Assim é possível gerar o índice de performance, ilustrado pela equação 2 abaixo:

$$
I_{p}=\frac{\sum V_{d}}{\sum V_{d, r e f}}(2)
$$

Onde:

$\mathrm{Vd}=$ valor do dano;

Vd,ref $=$ Valor de referência;

Ip = índice relativo .

\section{Caracterização da estrutura}

A obra na qual foi aplicado o modelo, é uma ponte de 240,00 metros de extensão e 13,40 metros de largura. Ela possui um traçado curvo em um trecho e ortogonal sobre o leito do rio, além de greide plano, com gabarito de 30 metros entre pilares e 8 metros até o banzo inferior da viga. As lajes são em concreto armado, assim como os pilares. A estrutura contava com 24 pilares sendo que $16 \mathrm{em}$ terra e oito no leito do reio. As dimensões entre um tipo e outro eram diferentes entre si, isso por conta do menor vão livre, nesse caso, 16 metros aproximadamente, para os em solo. Havia na obra 24 contraventamentos de pilares e 12 blocos em concreto armado.

$\mathrm{Na}$ região de transposição do rio, onde o vão era de 30 metros, as vigas foram reforçadas com um caixão metálico treliçado. Este ajuda a resistir a torção ocasionado pelo carregamento oriundo dos veículos circulando em somente uma 
FALAVIGNA, C.; SANTOS FILHO, M L., APLICAÇÃO DO MODELO MATEMÁTICO PARA RANQUEAMENTO DE OBRAS DE ARTE ESPECIAIS DESENVOLVIDO PELO ESCRITÓRIO MODELO DE ENGENHARIA CIVIL - EMEA/UFPR - UM ESTUDO DE CASO. $2^{\circ}$ Simpósio Paranaense de Patologia das Construções (20 SPPC), artigo 2SPPC1026, pp. 315-328, 2017. DOI:

faixa de tráfego. Além disso, suas extremidades (encontros) possuíam contenções de cortinas atirantadas.

O tabuleiro possuía pavimento asfáltico que totalizava 8,20 metros, protegidos com barreiras New Jersey, que separavam as faixas de tráfego do passeio. Este possuía guarda-corpos eram metálicos. Na interface entre $\mathrm{o}$ aterro de acesso e a ponte existiam juntas elastoméricas, além de mais duas para dilatação no decorrer da estrutura. A OAE também possuía aparelhos de apoio em articulações metálicas e em neoprene fretado.

Essa descrição da morfologia é importante, pois como a nota da obra é dada em virtude de um índice relativo, o valor de referência vai englobar todos os elementos da estrutura, ou seja, o não cadastramento de algum item gera uma nota que não é acurada. A tabela 6 ilustra todos os elementos presentes na obra:

Tabela 6: Morfologia da obra analisada

\begin{tabular}{cc}
\hline Quantidade & Elemento \\
\hline 1 & Sinalização \\
1 & Operação \\
2 & Aterro de acesso \\
1 & Drenagem \\
4 & Defensa metálica \\
12 & Bloco de concreto armado \\
3 & Laje de concreto armado \\
2 & Viga de concreto armado \\
24 & Contraventamento de pilar de concreto armado \\
24 & Pilar em colunas de concreto armado \\
1 & Viga metálica \\
24 & Aparelho de apoio de neoprene fretado \\
8 & Articulação metálica \\
2 & Encontro - Parede Frontal de concreto armado \\
2 & Muro de arrimo de concreto \\
2 & Junta de dilatação elastomérica \\
1 & Pavimento asfáltico \\
2 & Calçada de concreto armado \\
2 & Guarda corpo metálico \\
64 & Estaca metálica \\
49 & Transversina portante de concreto armado \\
2 & Barreira \\
\hline
\end{tabular}

Para auxiliar na inspeção é desenhado um croqui dos perfis longitudinal, transversal e vista superior, no qual é inserido o croqui de fotos, já que cada manifestação cadastrada deve possuir uma foto associada. A seguir, é ilustrado uma foto do perfil longitudinal (Fig. 1) e os croquis da respectiva OAE (Fig. 2 e 3). 
FALAVIGNA, C.; SANTOS FILHO, M L., APLICAÇÃO DO MODELO MATEMÁTICO PARA RANQUEAMENTO DE OBRAS DE ARTE ESPECIAIS DESENVOLVIDO PELO ESCRITÓRIO MODELO DE ENGENHARIA CIVIL - EMEA/UFPR - UM ESTUDO DE CASO. $2^{\circ}$ Simpósio Paranaense de Patologia das Construções (2० SPPC), artigo 2SPPC1026, pp. 315-328, 2017. DOI: $10.4322 / 2$ SPPC.2017.026

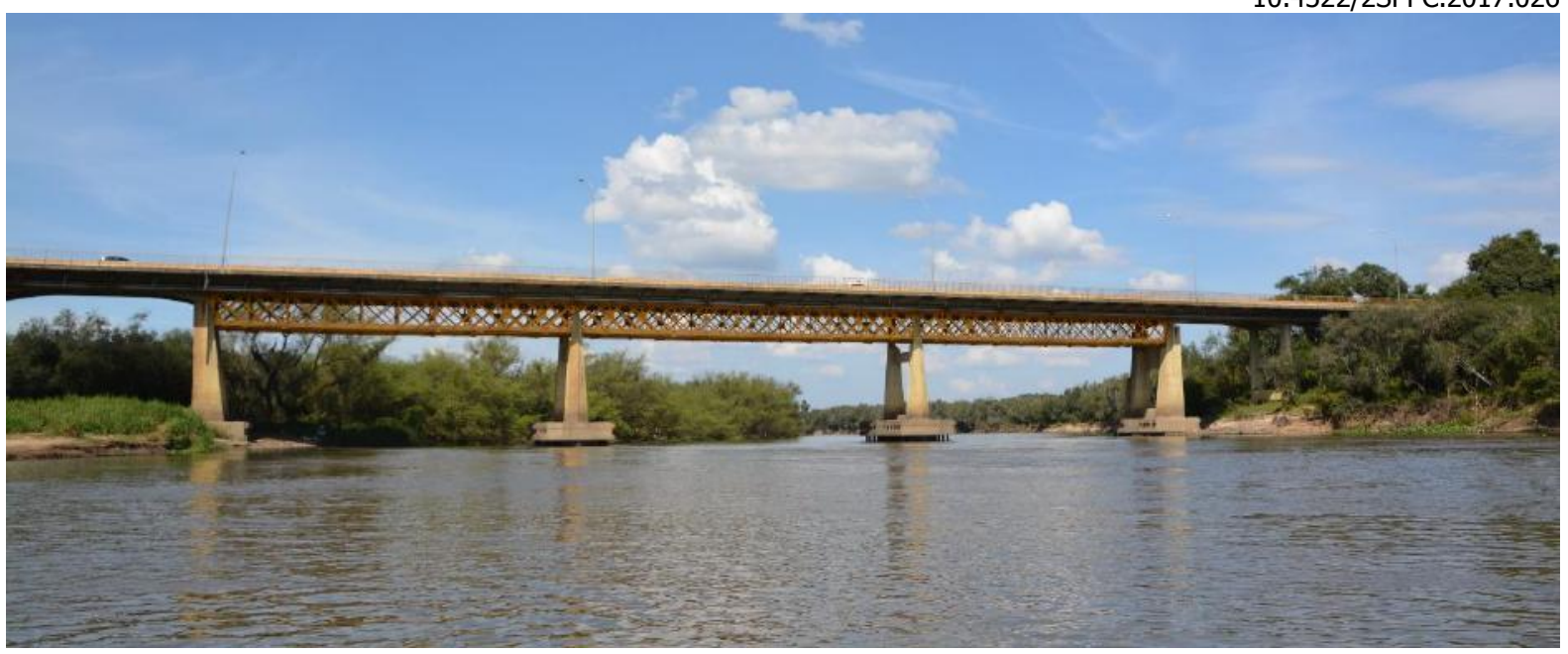

Figura 1: Foto do trecho sobre o rio da obra de arte especial analisada. Fonte: Acervo EMEA/UFPR.

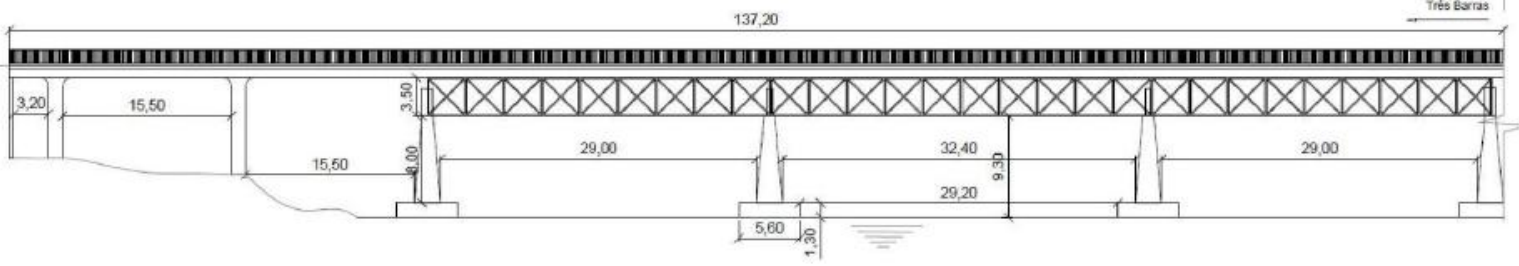

sto Noteus do Sul

105,50

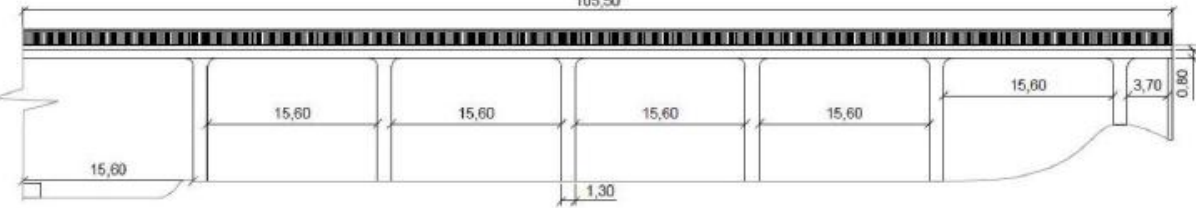

Figura 2: Croqui do perfil longitudinal da obra de arte especial analisada. Fonte: Acervo EMEA/UFPR.

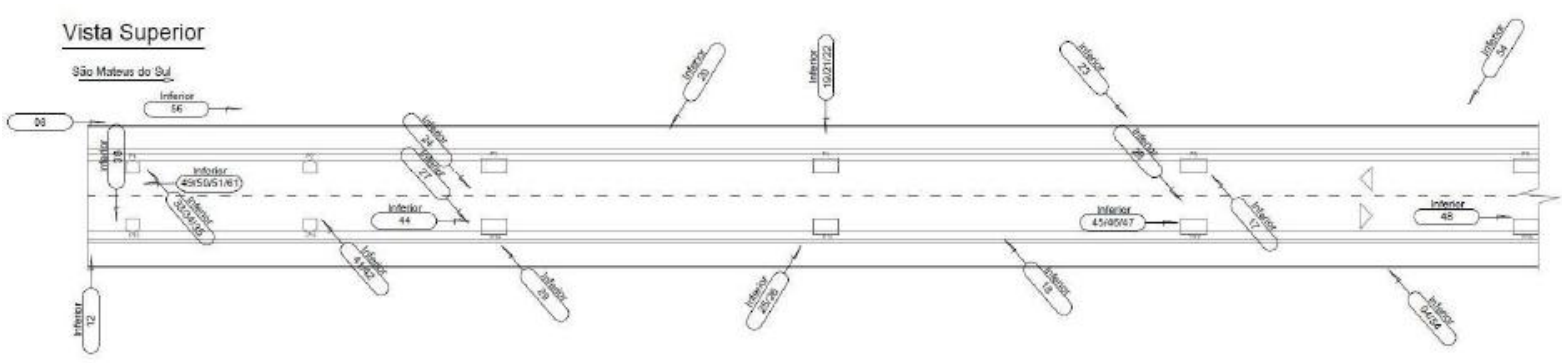

Figura 3: Perfil do croqui fotográfico da obra de arte especial analisada. Fonte: Acervo EMEA/UFPR. 
FALAVIGNA, C.; SANTOS FILHO, M L., APLICAÇÃO DO MODELO MATEMÁTICO PARA RANQUEAMENTO DE OBRAS DE ARTE ESPECIAIS DESENVOLVIDO PELO ESCRITÓRIO MODELO DE ENGENHARIA CIVIL - EMEA/UFPR - UM ESTUDO DE CASO. $2^{\circ}$ Simpósio Paranaense de Patologia das Construções (20 SPPC), artigo 2SPPC1026, pp. 315-328, 2017. DOI:

\section{Resultados}

Antes da aplicação do modelo matemático desenvolvido no EMEA/UFPR, é também preenchido uma ficha de avaliação conforme estabelece o DNIT 010/2004 - PRO [5], ilustrado a seguir. Percebe-se que nessa avaliação, não existe uma discretização das manifestações, onde estão alocadas especificamente e seus respectivos tamanhos, ou seja, a nota fica totalmente dependendo somente da experiência do inspetor. Nesse modelo, a nota técnica da OAE é definida pela pior nota atribuída aos grupos apresentados. A figura 4 é referente a ficha de inspeção utilizada para o método descrito, preenchida com valores para a ponte do estudo.

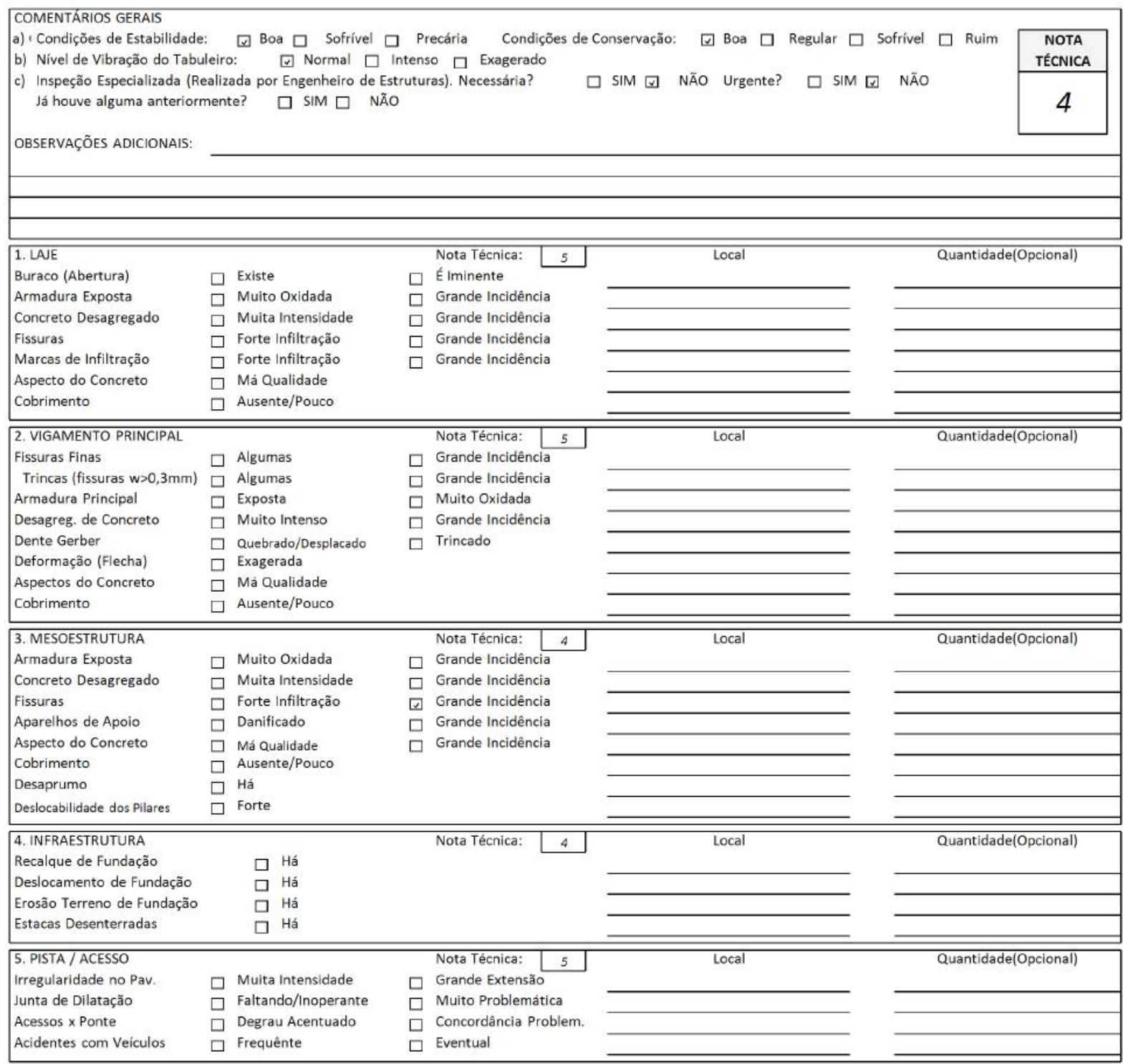

Figura 4: Ficha de inspeção DNIT 10/2004 - PRO. Fonte: Acervo EMEA/UFPR.

O modelo desenvolvido no EMEA/UFPR procura descrever melhor a manifestação, além de possuir pesos conforme descrito anteriormente, a deterioração é alocada a um elemento específico e não a família de elementos, como faz a inspeção sugerida pelo DNIT 010/2004. No relatório gerado, é apresentado a foto da manifestação além da identificação de qual elemento, a dimensão e reparo dentro das classificações da metodologia anteriormente descrita, além do tamanho da 
FALAVIGNA, C.; SANTOS FILHO, M L., APLICAÇÃO DO MODELO MATEMÁTICO PARA RANQUEAMENTO DE OBRAS DE ARTE ESPECIAIS DESENVOLVIDO PELO ESCRITÓRIO MODELO DE ENGENHARIA CIVIL - EMEA/UFPR - UM ESTUDO DE CASO. $2^{\circ}$ Simpósio Paranaense de Patologia das Construções ( $2^{\circ}$ SPPC), artigo 2SPPC1026, pp. 315-328, 2017. DOI: $10.4322 / 2$ SPPC.2017.026 respectiva manifestação. A seguir, é ilustrado como fica a descrição da manifestação (Fig. 5 a 7).

Elemento: Laje de Concreto Armado

Manifestação: Eflorescências, com

surgimento de manchas esbranquiçadas

$N^{\circ}$ do elemento: 1

Dimensão: Insignificante

Reparo: Dano à reparar

Tamanho: $0,7 \mathrm{~m}^{2}$

Observação:

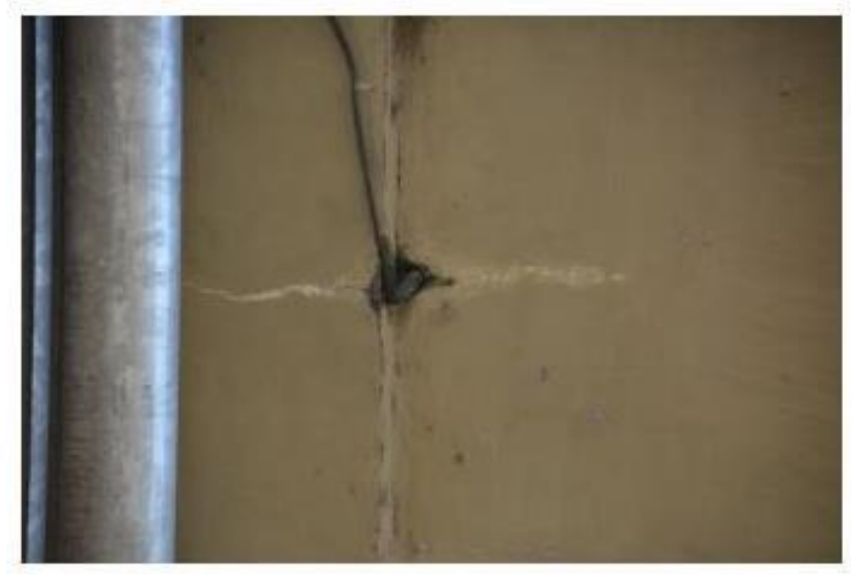

Figura 5: Apresentação da manifestação patológica - eflorescências - no relatório. Fonte: Acervo EMEA/UFPR

Elemento: Pilar em Colunas de Concreto Armado

Manifestação: Manchas de umidade

$N^{\circ}$ do elemento: 16

Dimensão: Média

Reparo: Dano à reparar

Tamanho: $8 \mathrm{~m}^{2}$

Observação:

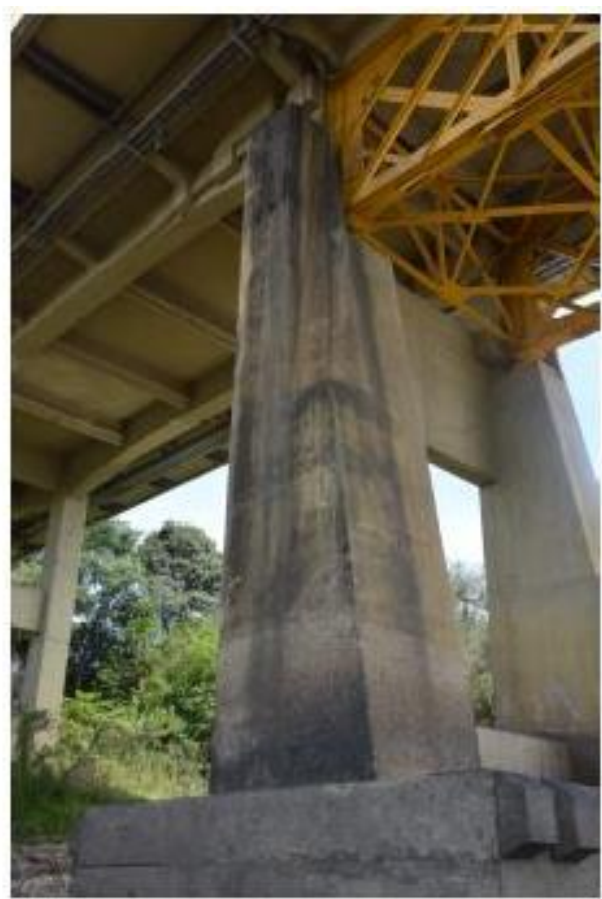

Figura 6: Apresentação da manifestação patológica - mancha de umidade - no relatório. Fonte: Acervo EMEA/UFPR 
FALAVIGNA, C.; SANTOS FILHO, M L., APLICAÇÃO DO MODELO MATEMÁTICO PARA RANQUEAMENTO DE OBRAS DE ARTE ESPECIAIS DESENVOLVIDO PELO ESCRITÓRIO MODELO DE ENGENHARIA CIVIL - EMEA/UFPR - UM ESTUDO DE CASO. $2^{\circ}$ Simpósio Paranaense de Patologia das Construções (20 SPPC), artigo 2SPPC1026, pp. 315-328, 2017. DOI:

Elemento: Pilar em Colunas de Concreto

Armado

Manifestação: Corrosão da armadura com

desplacamento de concreto

$N^{\circ}$ do elemento: 15

Dimensão: Pequena

Reparo: Dano à reparar

Tamanho: $0,15 \mathrm{~m}^{2}$

Observação:

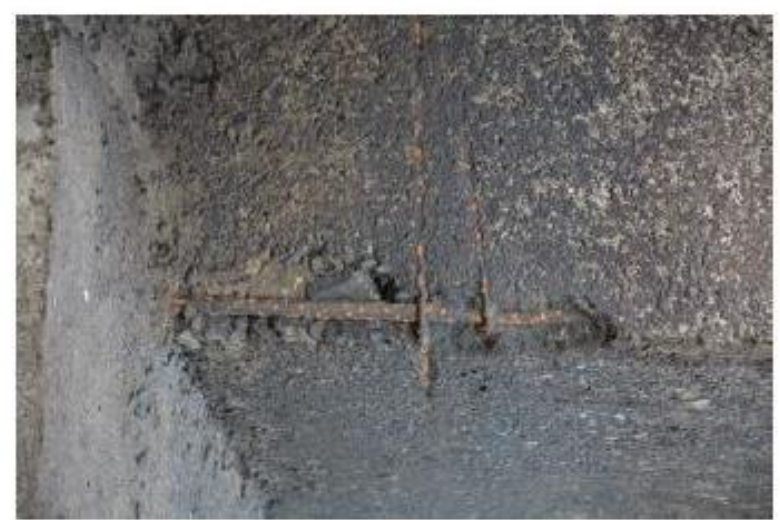

Figura 7: Apresentação da manifestação patológica - corrosão - no relatório. Fonte: Acervo EMEA/UFPR.

A seguir, é ilustrado a figura 8, que indica a aplicação do modelo matemáticos nos elementos (parâmetros) e, em seguida, o índice relativo da OAE analisada: 
FALAVIGNA, C.; SANTOS FILHO, M L., APLICAÇÃO DO MODELO MATEMÁTICO PARA RANQUEAMENTO DE OBRAS DE ARTE ESPECIAIS DESENVOLVIDO PELO ESCRITÓRIO MODELO DE ENGENHARIA CIVIL - EMEA/UFPR - UM ESTUDO DE CASO. $2^{\circ}$ Simpósio Paranaense de Patologia das Construções ( $2^{\circ}$ SPPC), artigo 2SPPC1026, pp. 315-328, 2017. DOI:

10.4322/2SPPC.2017.026

\begin{tabular}{|c|c|c|c|c|c|c|c|c|}
\hline Elemento & Manifestação & $\mathbf{N}^{0}$ & $\mathbf{B}$ & $\mathbf{K 1}$ & $\mathbf{K} 2$ & K3 & K4 & Ind. \\
\hline $\begin{array}{l}\text { Pilar em colunas de } \\
\text { concreto armado }\end{array}$ & Desgaste superficial & 4 & 1 & 0,4 & 1 & 0,5 & 2,5 & 0,5 \\
\hline Articulação metálica & Corrosão em elementos metálicos & 15 & 3 & 0,4 & 0,5 & 1 & 2,5 & 1,5 \\
\hline Laje de concreto armado & $\begin{array}{l}\text { Eflorescências com surgimento de } \\
\text { manchas esbranquiçadas }\end{array}$ & 1 & 1 & 0,4 & 0 & 1,5 & 2,5 & 0 \\
\hline Estaca metálica & $\begin{array}{l}\text { Corrosão em elementos metálicos } \\
\text { com perda de seção }\end{array}$ & 26 & 4 & 0,4 & 2 & 0,5 & 4 & 6,4 \\
\hline $\begin{array}{l}\text { Transversina portante de } \\
\text { concreto armado }\end{array}$ & $\begin{array}{l}\text { Armadura exposta por deficiência } \\
\text { de cobrimento sem corrosão }\end{array}$ & 4 & 2 & 0,3 & 0 & 0,5 & 2,5 & 0 \\
\hline $\begin{array}{l}\text { Pilar em colunas de } \\
\text { concreto armado }\end{array}$ & Manchas de umidade & 16 & 1 & 0,4 & 1 & 0,5 & 2,5 & 0,5 \\
\hline $\begin{array}{l}\text { Pilar em colunas de } \\
\text { concreto armado }\end{array}$ & $\begin{array}{l}\text { Corrosão da armadura com } \\
\text { desplacamento de concreto }\end{array}$ & 15 & 4 & 0,4 & 0,5 & 0,5 & 2,5 & 0,75 \\
\hline $\begin{array}{l}\text { Contraventamento de pilar } \\
\text { de concreto armado }\end{array}$ & Nicho e concretagem & 32 & 3 & 0,4 & 1,5 & 0,5 & 1 & 0,6 \\
\hline Bloco de concreto armado & $\begin{array}{l}\text { Corrosão da armadura com } \\
\text { desplacamento e perda de seção }\end{array}$ & 15 & 3 & 0,4 & 0,5 & 0,5 & 2,5 & 1 \\
\hline $\begin{array}{l}\text { Pilar em colunas de concreto } \\
\text { armado }\end{array}$ & Fissura em linha vertical & 24 & 3 & 0,4 & 0,5 & 2 & 2,5 & 3 \\
\hline $\begin{array}{l}\text { Pilar em colunas de concreto } \\
\text { armado }\end{array}$ & Fissura em linha vertical & 1 & 3 & 0,4 & 0,5 & 2 & 2,5 & 3 \\
\hline $\begin{array}{l}\text { Pilar em colunas de concreto } \\
\text { armado }\end{array}$ & Fissura em linha vertical & 23 & 3 & 0,4 & 0,5 & 2 & 2,5 & 3 \\
\hline $\begin{array}{l}\text { Pilar em colunas de concreto } \\
\text { armado }\end{array}$ & Fissura em linha vertical & 13 & 3 & 0,4 & 0,5 & 2 & 2,5 & 3 \\
\hline $\begin{array}{l}\text { Pilar em colunas de concreto } \\
\text { armado }\end{array}$ & Fissura em linha vertical & 12 & 3 & 0,4 & 0,5 & 2 & 2,5 & 3 \\
\hline $\begin{array}{l}\text { Pilar em colunas de concreto } \\
\text { armado }\end{array}$ & Fissura em linha vertical & 14 & 3 & 0,4 & 0,5 & 2 & 2,5 & 3 \\
\hline $\begin{array}{l}\text { Pilar em colunas de concreto } \\
\text { armado }\end{array}$ & Fissura em linha vertical & 11 & 3 & 0,4 & 0,5 & 2 & 2,5 & 3 \\
\hline $\begin{array}{l}\text { Pilar em colunas de concreto } \\
\text { armado }\end{array}$ & Fissura em linha vertical & 15 & 3 & 0,4 & 0,5 & 2 & 2,5 & 3 \\
\hline $\begin{array}{l}\text { Pilar em colunas de concreto } \\
\text { armado }\end{array}$ & Fissura em linha vertical & 17 & 3 & 0,4 & 0,5 & 2 & 2,5 & 3 \\
\hline $\begin{array}{l}\text { Pilar em colunas de } \\
\text { concreto armado }\end{array}$ & Fissura em linhas vertical & 18 & 3 & 0,4 & 0,5 & 2 & 2,5 & 3 \\
\hline $\begin{array}{l}\text { Contraventamento de pilar } \\
\text { de concreto armado }\end{array}$ & Fissura em linha vertical & 2 & 3 & 0,4 & 0,5 & 1 & 2,5 & 1,5 \\
\hline
\end{tabular}

Figura 8: Apresentação do relatório da aplicação do modelo matemático EMEA/UFPR sobre a estrutura. Fonte: EMEA/UFPR.

Com essas manifestações, o índice base da ponte (somatório dos valores de referência) ficou em 750, já o índice de performance é o somatório dos itens em negrito na figura anterior. Esse valor ficou igual a 15,75. Fazendo a divisão de um pelo outro, obtém-se o índice relativo que nesse caso ficou igual à 0,0210.

\section{Conclusões}

Aplicando-se o modelo desenvolvido na UFPR, percebe-se que esse gera informações mais detalhadas que o a inspeção proposta pelo DNIT 010/2004 PRO. Ao se agrupar os elementos em famílias (laje, vigamento principal, mesoestrutura, infraestrutura e pista/acesso) as informações específicas de cada elemento ficam perdidas, pois essas ficam macro avaliadas. A inspeção também gera como nota 
FALAVIGNA, C.; SANTOS FILHO, M L., APLICAÇÃO DO MODELO MATEMÁTICO PARA RANQUEAMENTO DE OBRAS DE ARTE ESPECIAIS DESENVOLVIDO PELO ESCRITÓRIO MODELO DE ENGENHARIA CIVIL - EMEA/UFPR - UM ESTUDO DE CASO. $2^{\circ}$ Simpósio Paranaense de Patologia das Construções (20 SPPC), artigo 2SPPC1026, pp. 315-328, 2017. DOI:

para a OAE, a pior avaliação dos itens descritos na ficha, não possibilitando saber o real estado da estrutura.

O modelo do EMEA/UFPR não tem esses problemas, pois cada elemento é avaliado, sendo a nota gerada por parâmetros estabelecidos e não apenas pela subjetividade de quem inspeciona. Outra vantagem, é que, decorrente do índice relativo, as notas podem ser melhor diferenciadas. Ou seja, duas estruturas podem ter nota técnica igual na inspeção do DNIT (por exemplo, 4) porém no modelo do EMEA/UFPR será muito difícil as notas serem exatamente iguais, visto a inspeção e nota ser atribuída utilizando todos os elementos.

Com essa avaliação mais minuciosa, caso uma recuperação seja feita na obra, é possível gerar orçamentos bem mais precisos, já que os danos estão cadastros por elemento estrutural e por meio de uma medida, assim o responsável consegue estimar com mais precisão o gasto que terá no reparo.

Com o avanço da tecnologia BIM, informações cada vez mais precisas são essenciais para os parâmetros que os programas envolvidos utilizam. Portanto, modelar uma estrutura locando exatamente onde se encontra cada manifestação, torna-se de grande valia ao arquétipo de informações, já que se pode assim otimizar custos e prazos para a manutenção. Nisso, podem ser feitos estudos do qual analisem os efeitos dos danos sobre várias frentes, como estrutural, de manutenção, de cronograma para os reparos, partindo sempre da ponte no pior estado, que é gerado pelo modelo de ranqueamento.

\section{Agradecimentos}

À Universidade Federal do Paraná, ao Setor de Tecnologia da UFPR, ao Departamento de Construção Civil - UFPR, ao Programa de Pós-graduação em Engenharia de Construção Civil (PPGECC), ao Departamento de Hidráulica e Saneamento da UFPR pelo empréstimo do barco para a realização da inspeção, o prof. PhD. Cristóvão Vicente Scapulatempo Fernandes por acompanhar e navegar o barco na inspeção e aplicação do modelo, ao Escritório Modelo de Engenharia Civil - EMEA/UFPR, e principalmente ao Departamento Nacional de Infraestrutura de Transportes - DNIT pelo projeto de extensão e pesquisa que resultaram no desenvolvimento da ferramenta descrita nesse artigo.

\section{Referências}

[1] SITTER, W.R. (1984). Costs for Service Life Optimization. The "Law of Fives". CEB-RILEM Durability of Concrete Structures.

[2] LICHTENSTEIN, Noberto B. (1985). Procedimento para formulação de diagnósticos de falhas e definição de conduta adequada à recuperação de edificações. Dissertação - Escola Politécnica, Universidade de São Paulo, p. 191. São Paulo, 1985.

[3] EUROPEAN CO-OPERATION IN THE FIELD OF SCIENTIFIC AND TECHNICAL RESEARCH. (2007) .COST 345: Methods used in the european states and assess the condition of highway structures. .Disponível em: 
FALAVIGNA, C.; SANTOS FILHO, M L., APLICAÇÃO DO MODELO MATEMÁTICO PARA RANQUEAMENTO DE OBRAS DE ARTE ESPECIAIS DESENVOLVIDO PELO ESCRITÓRIO MODELO DE ENGENHARIA CIVIL - EMEA/UFPR - UM ESTUDO DE CASO. $2^{\circ}$ Simpósio Paranaense de Patologia das Construções (2० SPPC), artigo 2SPPC1026, pp. 315-328, 2017. DOI:

<http://cost345.zag.si/Reports/COST_345_WG23.pdf>. Acesso em 21 ago. 2016

[4] COMITÉ EURO-INTERNACIONAL DU BETÓN. (1998). Bulletin 243: Strategies for Testing and Assessment of Concrete Structures. Suíça.

[5] DEPARTAMENTO NACIONAL DE INFRAESTRUTURA DE TRANSPORTES. DNIT 010/2004 - PRO: Inspeções em pontes e viadutos de concreto armado e protendido. Rio de Janeiro, 2004. 